\title{
O DESEMPENHO INOVADOR DE INCUBADORAS MISTAS: DESAFIOS DO AMBIENTE INSTITUCIONAL
}

Alan Barros Ferraz ${ }^{1}$

Ricardo Augusto Bonotto Barboza ${ }^{1}$

Geralda Cristina De Freitas Ramalheiro ${ }^{2}$

Sérgio Azevedo Fonseca ${ }^{3}$

\footnotetext{
${ }^{1}$ Universidade de Araraquara (UNIARA)

${ }^{2}$ Universidade de Araraquara - UNIARA

${ }^{3}$ Universidade Estadual Paulista "Júlio de Mesquita Filho"
} 


\section{O DESEMPENHO INOVADOR DE INCUBADORAS MISTAS: DESAFIOS DO AMBIENTE INSTITUCIONAL}

Resumo: Diversos instrumentos de políticas públicas foram criados para facilitar a inserção e a permanência das micro e pequenas empresas em redes de inovação, tais como: os Arranjos Produtivos Locais (APLs), os Parques Tecnológicos, as Incubadoras de Empresas, as Redes Temáticas de Centros de Inovação, o Serviço Brasileiro de Respostas Técnicas (SBRT) entre outros. Esse estudo teve como objetivo relatar as vantagens, as limitações e as dificuldades à operacionalização de um desses instrumentos, as Incubadora de Empresas. Através de um estudo de caso, viabilizado por pesquisa documental, entrevistas e observações, contatou-se que há uma baixa propensão autônoma das micro e pequenas empresas não tecnologias para a inovação. Os resultados da pesquisa permitem apontar, em caráter conclusivo, que a atuação efetiva de mecanismos de políticas públicas pode contribuir fortemente para a quebra de barreiras e resistências para a geração ou a incorporação de inovações pelas micro e pequenas empresas - tanto tradicionais quanto tecnológicas.

Palavras-chave: Inovação. Incubadora de Empresa. Empresa tecnológica. Empresa tradicional.

\section{Introdução}

Como mostrava Schumpeter (1961), já na primeira metade do século 20, a inovação é fator crítico de sobrevivência empresarial, condição essa acentuada a partir do início do século XXI, caracterizado por mudanças e volatilidades aceleradas, novas tecnologias e novas formas organizacionais. Nessas condições torna-se crucial que as empresas possuam capacidade de gerar e absorver inovações (BARGE-GIL, 2010; DOH; KIM, 2014; HOFFMANN; AMAL; MAIS, 2011; RADAS; BOŽIĆ, 2009; SOLOMON et al., 2013; SPITHOVEN; CLARYSSE; KNOCKAERT, 2011).

Nota-se que os tipos de inovação mais frequentes, adotados por empreendimentos de pequeno porte, são qualificados como inovações não tecnológicas ou inovações de baixa complexidade - low-tech innovations (BARGE-GIL, 2010; HEIDENREICH, 2009; NUNES; SERRASQUEIRO; LEITÃO, 2012) e que o percurso pelo qual a extensa maioria incorpora inovações pode ser enquadrado no conceito de inovações abertas (HEIDENREICH, 2009; TÖDTLING; LEHNER; KAUFMANN, 2009; VRGOVIC et al., 2012), tal como definido por Chesbrough (2003).

Radas e Božić (2009) defendem que os fatores que influenciam a inovação nas micro e pequenas empresas podem ser divididos em internos e externos, os primeiros referidos a características e políticas das MPE, os últimos às oportunidades que as MPE podem aproveitar do ambiente. Doh e Kim (2014) notaram que, no contexto das pequenas empresas, a inovação em produtos é vista como o resultado do investimento em competitividade por diferenciação e como estratégia de expansão do mercado e que as inovações em processos surgem como uma estratégia de competitividade por preços e como um caminho para a eficiência.

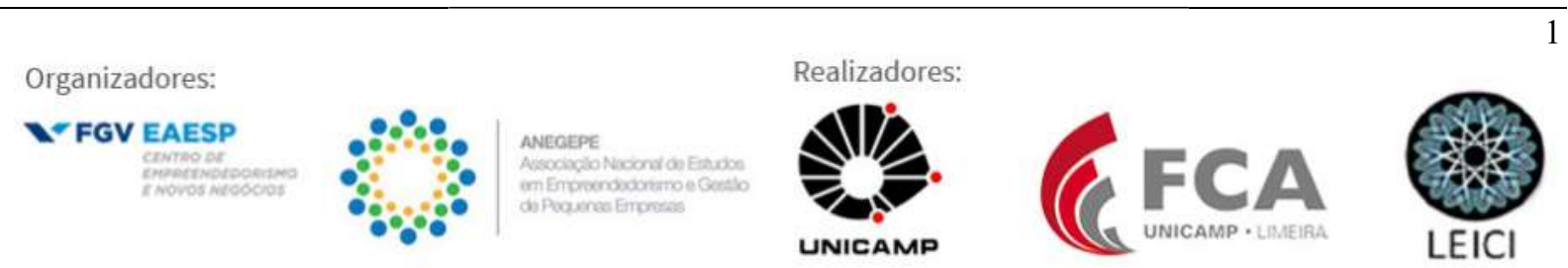


Em relação às indústrias tradicionais, e que são predominantemente caracterizadas pela presença de micro e pequenas empresas, constatou-se que as mesmas apresentam limitações para executar atividades de P\&D e para gerar inovações (SPITHOVEN; CLARYSSE; KNOCKAERT, 2011). Como evidenciou Barge-Gil (2010) as empresas fora dos setores de alta tecnologia, as empresas menores e, em certa medida, as empresas com baixa intensidade de $\mathrm{P} \& \mathrm{D}$, inovam, frequentemente, por meio da cooperação, isso porque o número e a qualificação dos funcionários de muitas dessas empresas caem abaixo de uma massa crítica necessária (SPITHOVEN; CLARYSSE; KNOCKAERT, 2011). Os apontamentos de Mcguirk, Lenihan e Hart (2015) revelam que os trabalhadores de pequenas empresas que participam de treinamento têm maiores probabilidades de participarem de atividades inovativas. Outro fator propulsor da inovação em pequenas empresas são as participações em redes (DOH; KIM, 2014).

No que tange às dificuldades das MPE para inovar, a literatura (BARGE-GIL, 2010; DOH; KIM, 2014; HUIZINGH, 2011; MCGUIRK; LENIHAN; HART, 2015; MCKELVEY; ZARING; LJUNGBERG, 2014; RADAS; BOŽIĆ, 2009; SOLOMON et al., 2013; SPITHOVEN; CLARYSSE; KNOCKAERT, 2011) aponta a existência de um conjunto de fatores restritivos, sendo os principais: o fato de operarem em segmentos de mercado estáveis; ofertarem produtos de baixa complexidade técnica; adotarem processos de trabalho rígidos; possuírem administração tradicional (familiar); contratarem trabalhadores com baixa qualificação profissional; adotarem processos inovativos apenas pontuais e de caráter corretivo; utilizarem tecnologia agregada por fornecedores; buscarem resultados em curto prazo (falta de visão e planejamento de longo prazo); manterem distanciamento com universidades e centros de pesquisa e pouco controle sobre o ambiente externo. Esse conjunto de fatores, inibidores de processos e atividades passíveis de criarem ambientes favoráveis à inovação, no contexto das micro e pequenas empresas, dos empreendimentos informais e dos empreendedores de baixa cultura e formação tecnológica, oferecem o desafio, à universidade, ao governo e aos próprios empreendimentos, para conceberem, implementarem e operacionalizarem instrumentos e mecanismos indutores de inovações (HOFFMANN; AMAL; MAIS, 2011).

Neste contexto destacam-se as estruturas em redes para facilitar a operacionalização da cooperação e dos estímulos à inovação. No cenário brasileiro, diversos instrumentos de políticas públicas foram criados para facilitar a inserção e a permanência das micro e pequenas empresas em redes de inovação, tais como: os Arranjos Produtivos Locais (APLs), os Parques Tecnológicos, as Incubadoras de Empresas, as Redes Temáticas de Centros de Inovação, o Serviço Brasileiro de Respostas Técnicas (SBRT) entre outros. O objetivo deste trabalho é relatar as vantagens, as limitações e as dificuldades à operacionalização da inovação nos ambientes institucionais que as incubadoras mistas operam. Adicionalmente, buscou-se verificar a periodicidade com que as empresas assistidas inovaram, analisando os tipos, fontes e mecanismos usados para a promoção das inovações. O texto está estruturado em cinco seções: esta primeira, introdutória; a segunda, em que são tecidas breves considerações em torno do referencial teórico; a terceira contempla a estratégia metodológica utilizada na pesquisa; a quarta evidencia os resultados da pesquisa; na última são apresentadas as considerações finais.

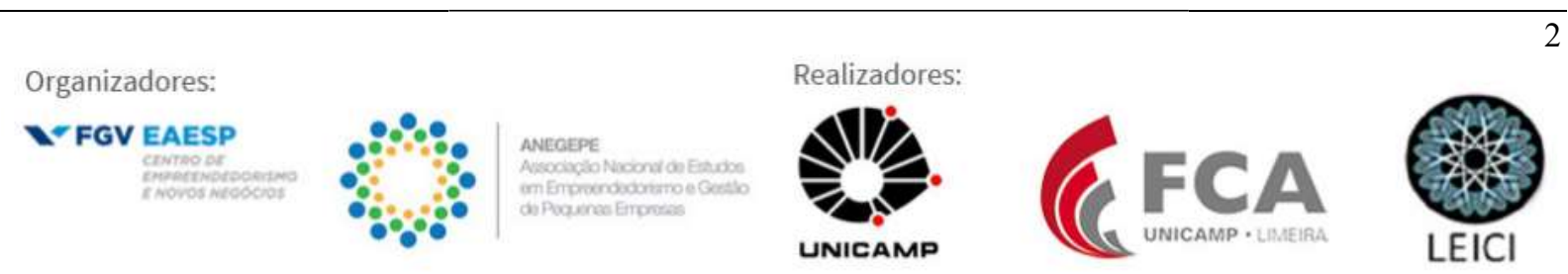




\section{Referencial teórico}

As incubadoras de empresas são organizações estabelecidas e difundidas que apoiam atividades de empreendedorismo. No panorama geral, os programas de incubação apresentam diversas virtudes: no plano econômico propiciam o fortalecimento da competitividade das empresas apoiadas, o aumento da arrecadação tributária gerada e a dinamização das economias locais; na esfera social contribuem para a melhoria da qualidade de vida da sociedade como um todo, isso porque estimulam a geração de postos de trabalho e renda; no âmbito político, sistematizam parcerias para conduzir as atividades de incubação e fortalecer o espírito associativista e articulam a comunidade para a criação de aparato legal que fortaleça os micro e pequenos empreendimentos; em termos culturais, percebe-se que as incubadoras são estruturas organizacionais que, nos seus mais diversos formatos e, independente de suas origens, acabam se enraizando e criando vínculos estreitos com as comunidades locais nas quais se instalam; é possível também, admitir o potencial da geração de benefícios ambientais, caso atuem pela minimização das dificuldades enfrentadas pelas empresas abrigadas na adoção de práticas de gestão ambiental; por fim, estas organizações podem ser usadas como injeções de vitamina para regiões "cansadas" e, como estimuladores de contração ou analgésicos no nascimento de spin-offs universitárias.

Para alcançar efetividade de suas características e alcançar a plenitude das virtudes listadas acima, as incubadoras ofertam serviços capazes de fortalecer os empreendimentos assistidos, minimizando as taxas de mortalidade e ampliando as taxas de sucesso. Um dos serviços ofertados são os espaços físicos, tanto individuais quanto compartilhados, que proporcionam economia de escala e redução de custos. Estes espaços geralmente são constituídos por recepção, serviços de escritório, salas de reuniões, salas de conferências, estacionamento, laboratórios, equipamentos de pesquisa e instalações para produção. Outro serviço disponibilizado são atividades que aceleram a curva de aprendizado e proporcionam capacitação gerencial para as empresas assistidas, geralmente em formatos de coaching e treinamento. Por fim, ofertam também, acesso às redes tecnológicas, profissionais e financeiros que são capazes de facilitar o acesso aos recursos externos, ao conhecimento e a legitimidade das atividades executadas pelos incubados (BRUNEEL et al., 2012).

Destaca-se que o movimento de criação destas organizações ocorre ha seis décadas. A primeira incubadora de empresas surgiu no final da década de 1950 nos Estados Unidos (EUA). Este movimento ganhou relevância nos anos 80, quando o conceito foi consolidado e difundido (de acordo com a National Business Incubator Association - NBIA, havia 12 incubadoras de empresas nos EUA em 1980). A onda inicial de expansão incluiu países desenvolvidos, principalmente os Estados Unidos, o Reino Unido e a Europa continental. Ao longo das duas últimas décadas, o número total de incubadoras cresceu significativamente em todo o mundo. Atualmente existem mais de 7000 incubadoras em funcionamento, conforme estimado pela NBIA (MRKAJIC, 2017; WEELE; RIJNSOEVER; NAUTA, 2017).

Com o movimento histórico o conceito foi se estruturando e ganhando contornos característicos. Delimita-se que a oferta do espaço físico caracterizou as incubadoras da primeira geração, os serviços de capacitação caracterizaram as incubadoras da segunda geração e os acessos às redes caracterizaram as incubadoras de terceira geração (BERGEK; NORRMAN, 2008; BRUNEEL et al., 2012). Recentemente, surgiu uma quarta geração de incubadoras, conhecidas pelo termo de aceleradoras que são caracterizados como um
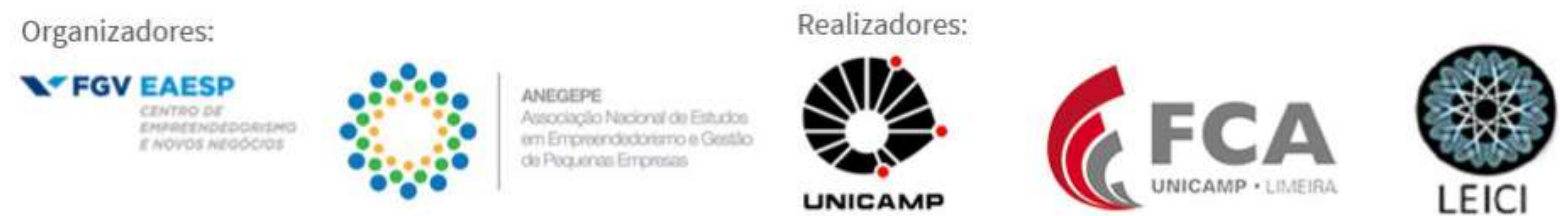
programa mais intensivo e focado, adaptado para lançar ideias de negócios de alto potencial direto ao mercado em um período de tempo relativamente curto e predefinido (PAUWELS et al., 2015).

Apesar dos diversos benefícios propiciados pelas incubadoras, nem todos os programas alcançam o sucesso. A próxima seção evidencia fatores que interferem no desempenho dos programas de incubação.

\subsection{Incubadoras de empresas em contextos institucionais}

A literatura sugere que um ambiente institucional vazio cria desafios mais severos ao empreendedorismo. As falhas no mercado e as falhas governamentais minam e criam barreiras para a formação de novas empresas, delimita-se, por exemplo, que a escassez de habilidades empresariais, a falta de financiamento empresarial disponível e a ausência de redes empresariais extensas e efetivas, são prejudiciais para a nova atividade comercial. De forma complementar, observa-se que as lacunas institucionais tipicamente presentes nos países em desenvolvimento afetam a educação, a legitimidade, a cultura empresarial e o acesso aos recursos, que também são críticos para o empreendedorismo (MRKAJIC, 2017).

Essas falhas criam um conjunto de externalidades negativas para o empreendedor, o que implica a necessidade da projeção de modelos de incubação com características próprias Acentua-se assim, que o sucesso dos programas de incubação esta intrinsecamente ligado ao contexto institucional e ao ambiente em que o programa foi inserido (BERMÚDEZ; MORAIS, 1998; BHABRA-REMEDIOS; CORNELIUS, 2003; CHAN; LAU, 2005);

Nota-se que a literatura sobre incubadoras em países em desenvolvimento ainda deve ser consolidada. Os pesquisadores tentaram abordar a questão do impacto que as incubadoras de empresas podem ter no desenvolvimento econômico (por exemplo, Ratinho e Henriques, 2010), e muito menos atenção foi dedicada ao seu papel no ecossistema de empreendedorismo e na organização interna (MRKAJIC, 2017). Além de alguns estudos aplicados (ADEGBITE, 2001; LALKAKA, 2003; SCARAMUZZI, 2002), não foi sugerido nenhum quadro teórico convincente. Apenas muito recentemente, Dutt et al. (2015) realizou um estudo abrangente com base na análise em países em desenvolvimento e afirmou que as incubadoras podem preencher os vazios institucionais, ao enquadrá-los como um tipo de intermediário entre empreendedores e seu meio ambiente. Eles afirmam que, dependendo do nível de avanço do ambiente institucional, as incubadoras concentram seus serviços no desenvolvimento de capacidades empresariais ou no desenvolvimento de infra-estrutura de mercado.

Uma outra possível explicação para o desempenho decepcionante de algumas incubadoras é que as empresas em fase inicial não aproveitam ao máximo os recursos oferecidos pela incubadora (WEELE; RIJNSOEVER; NAUTA, 2017). Por exemplo, enquanto as incubadoras organizam programas de treinamento e coaching para que os empresários adquiram os conhecimentos necessários ao desenvolvimento da empresa, a participação nessas sessões tende a ser baixa (PATTON; MARLOW, 2011; PATTON, 2014). Da mesma forma, as incubadoras buscam aproximar os empreendedores com atores e instituições externas, mas muitos empresários não se envolvem nessas atividades de rede (BRUNEEL et al., 2012; SCHWARTZ; HORNYCH, 2010). Esses achados sugerem que os empreendedores e a equipe da incubadora têm percepções diferentes sobre a importância dos recursos da incubadora: enquanto a equipe da incubadora sente que seu treinamento e o
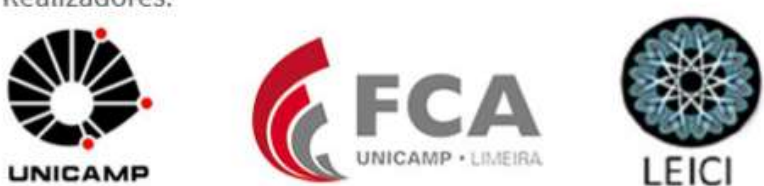
networking são de grande importância para as empresas em fase de incubação; os empresários, aparentemente, não concordam com esta afirmativa (WEELE; RIJNSOEVER; NAUTA, 2017).

Parte da explicação para este quadro reside no fato de que os empresários preferem não usar os recursos da incubadora quando estes são de qualidade insuficiente, um exemplo seria a mentoria fornecida por mentores que não possuem experiência (LALKAKA, 2001; RICE, 2002). De forma complementar acentua-se que, em alguns casos, há uma incompatibilidade entre os recursos fornecidos pelas incubadoras e os recursos necessários para as empresas. Ratinho e Henriques (2010) argumentam que os serviços da incubadora são, em certas unidades, muito rígidos, uma vez que não são adaptados às necessidades específicas das empresas. Em outras situações, Bruneel et al. (2012) contatou que os recursos da incubadora são supérfluos, já que as incubadoras apoiam empresas maduras que já possuem uma sólida base de recursos. Essas empresas maduras não precisam do suporte da incubadora, que é mais adaptada às necessidades de empresas em estágio inicial. Uma terceira explicação aponta que os empreendedores incubados muitas vezes têm uma base tecnológica e pouca experiência empresarial, tais empreendedores podem não reconhecer as lacunas em sua base de recursos, tornando-se ser incapazes de reconhecer o valor dos recursos da incubadora (PATTON, 2014). Há ainda, um desajuste adicional, entre os recursos que os empreendedores querem quando iniciam o processo de incubação e os recursos que os empreendedores precisam para complementar a sua base de recursos. Muitas vezes, são incapazes de reconhecer suas lacunas de recursos e não estão dispostos a fazer os investimentos necessários no desenvolvimento de recursos que faltam, porque hesitam em sair de sua zona de conforto. Isso explica por que esses empresários não podem usar os recursos fornecidos pelas incubadoras, mesmo quando os recursos são de qualidade suficiente e de acordo com as necessidades do empreendimento (WEELE; RIJNSOEVER; NAUTA, 2017).

Neste quadro fica evidente que a incubadora deve buscar novas formas de atuação. Se os recursos da incubadora são de qualidade insuficiente ou não estão de acordo com as necessidades das empresas devem se concentrar no desenvolvimento de seus recursos e ouvir com mais atenção as necessidades dos empresários. Por outro lado, se os empresários não estão suficientemente conscientes das suas necessidades, então apenas fornecer recursos a pedido dos empresários não é suficiente para o bom desempenho das incubadoras. Elas devem, então, identificar ativamente as necessidades das empresas e estimular os empreendedores a utilizar os recursos da incubadora. Devem estabelecer uma estratégia forte de intervenção, auxiliando os empreendedores a reconhecer suas lacunas de recursos e estimulando-os a desenvolver os recursos em falta (WEELE; RIJNSOEVER; NAUTA, 2017).

Completando esta análise, evidencia-se que os programas de incubação devem buscar a diferenciação e o alinhamento, externo e interno, para alcançar benefícios de desempenho (VANDERSTRAETEN; MATTHYSSENS, 2012). Os autores sugerem que as escolhas do setor e áreas de tecnologias definirão o escopo competitivo de uma incubadora e que a oferta de serviços que agregue valor aos incubados permitirá a diferenciação e a longevidade das atividades desempenhadas. Consequentemente, o alcance da diferenciação e do alinhamento será resultante do estabelecimento de uma estratégia clara e concisa, que atenda as necessidades dos stakeholders envolvidos no programa de incubação. Desta forma a estratégia adotada será um fator preponderante ao alcance do êxito (FONSECA, 2010;
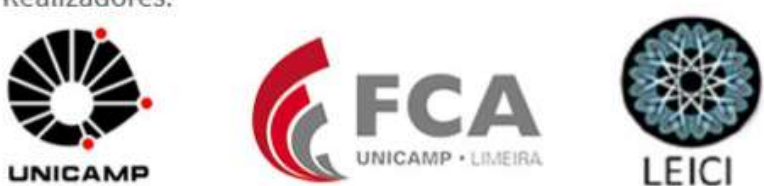
VANDERSTRAETEN; MATTHYSSENS, 2012). Neste mesmo viés, Alsos, Hytti e Ljunggren (2011) enfatizam que gerir e responder às demandas das partes interessadas é um dos pontos mais críticos na definição do sucesso ou fracasso dos diferentes modelos de incubadora. Sendo assim, percebe-se que as incubadoras devem personalizar os serviços entregas aos incubados. Além de personalizar, devem flexibilizar o acesso aos serviços disponibilizados (VANDERSTRAETEN, 2016).

Salienta-se que em muitos casos, os empresários procuram a incubadora, principalmente, para acessar o capital físico e o capital financeiro e hesitam em participar do processo de incubação para desenvolver o conhecimento empresarial (WEELE; RIJNSOEVER; NAUTA, 2017). Este característica, componente do mix cultural da organização, deve ser alterada. Ahmad (2014) pondera que os componentes culturais são fatores preponderantes para o sucesso ou fracasso das incubadoras.

Tendo esta discussão como plano de fundo, este trabalho buscou investigar o desempenho de um programa de incubação, em fornecer um serviço específico, no caso o apoio à inovação. Dentro da investigação foi analisado: a influencia do ambiente institucional, com a respectiva caracterização da existência, ou não de vazios institucionais; a qualidade do serviço fornecido; a participação dos empreendedores; e as características culturais do ambiente. A fim de suportar esta análise, a próxima seção referencia brevemente o contexto da inovação em programas de incubação.

\subsection{O papel da incubadora na promoção da inovação}

Como mostra a literatura, as incubadoras de empresas são demandadas a investir em ações indutoras de inovações (WONGLIMPIYARAT, 2016; ZHAO; ZHANG; WU, 2017; XIAO; NORTH, 2017; APA; GRANDINETTI; SEDITA, 2017; FONSECA, 2010; FURLANETTO, 2006; RAMALHEIRO, FONSECA, TERENCE, 2010). Monsson e Jørgensen (2016) acentuam que as incubadoras de empresas podem ser facilmente implementadas, mesmo em regiões com sistemas de inovações fracos. Nota-se que essa popularidade baseia-se na crença de que esses mecanismos fornecem insumos críticos de valor agregado essenciais para a criação e desenvolvimento de firmas inovadoras (MIAN; LAMINE; FAYOLLE, 2016).

Salienta-se que as incubadoras estimulam a inovação, pois minimizam os custos operacionais das unidades incubadas, permitem a aproximação de investidores e ampliam a probabilidade de inserção de capital na nova idéia. Além disso, podem dispor de laboratórios, técnicos especializados e parcerias institucionais com universidades e centros de pesquisa (RUBIN; AAS; STEAD, 2015; FONSECA, 2010; BARBOZA; FONSECA; RAMALHEIRO, 2017). Constata-se, porém, que muitas não apresentam competências internas suficientes para fomentar inovações, ficam dependentes de parcerias externas para o alcance desse objetivo. Nos casos em que as incubadoras não investem em ações indutoras de inovações (realidade presente em muitas incubadoras mistas e tradicionais) a capacidade de fortalecimento das empresas assistidas acaba prejudicada (RAMALHEIRO, FONSECA; TERENCE, 2010). Alguns autores apontam que os principais problemas enfrentados pelas incubadoras não tecnológicas no estimulo a inovações são: a inexistência ou precariedade da oferta de infraestrutura laboratorial e de corpo técnico (que demandam altos investimentos, muitas
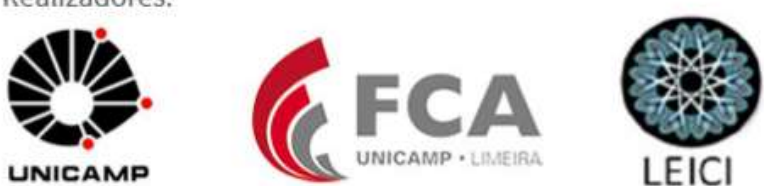
vezes escassos) e a dificuldade de se vincularem a redes e sistemas de apoio à inovação (FONSECA, 2010; FURLANETTO, 2006; BARBOZA; FONSECA; RAMALHEIRO, 2017).

Neste contexto, um diferencial capaz de promover inovação, mesmo em situações onde as incubadoras não são tecnológicas, seria a competência do gerente da incubadora. Apa, Grandinetti e Sedita (2017) acentuam que para a promoção da inovação, o papel dos gerentes das incubadoras é duplo. Por um lado, funciona como intermediário, induzindo e facilitando os relacionamentos dos incubados, oferecendo-lhes a possibilidade de aproveitar a reputação da incubadora, o que ajuda a legitimar suas atividades e mitigar a responsabilidade da novidade. Por outro lado, também desenvolve interações intensas, transmitindo informações e conhecimento relevantes. Complementando a análise, Redondo e Camarero (2017), notam que os gerentes devem apresentar experiência no mundo empresaria. Aqueles que não possuem um perfil empreendedor enfraquecem o acesso dos incubado a outras redes de negócios e se mostram menos eficientes no treinamento dos empreendedores e no estímulo à inovação.

Tendo este referencial consolidado, a seção seguinte apresentará a metodologia adotada na pesquisa.

\section{Metodologia}

A estratégia metodológica utilizada compreendeu uma pesquisa qualitativa, de caráter exploratório, delineada como estudo de casos simples, com dados coletados por meio de entrevistas, analise documental e observação participante. A pesquisa foi realizada entre os meses de junho e dezembro de 2017, com dois grupos de investigação, o primeiro composto pelos coordenadores da Incubadora e o segundo com os empreendimentos incubados.

O primeiro procedimento foi um mapeamento das empresas que foram atendidas pelo programa de incubação em um período de dois anos (outubro de 2015 a novembro de 2017). Neste mapeamento, buscou-se classificar as empresas em cinco grupos: Empresas não atendidas e que não inovaram; Empresas não atendidas e que inovaram; Empresas atendidas e que não inovaram; Empresas atendidas e que inovaram; e Empresas em fase inicial de incubação. Esta classificação levou em consideração os seguintes aspectos:

- Empresas não atendidas: são empresas que foram incubadas e que utilizaram os recursos da incubadora de forma pontual e não sistematizada;

- Empresa atendida: empresas que foram incubadas e que tiveram um plano de incubação robusto e sistematizado, para fornecer a gama de recursos necessários ao pleno desenvolvimento do empreendimento;

- Empresa inovadora: aquela que introduziu novidades na operacionalização do negócio, seja no âmbito interno da organização, seja no âmbito externo; seja essa novidade de alta, média ou baixa complexidade;

- Empresa não inovadora: aquela empresa que não apresentou nem uma novidade no mercado ou que não mudou em nada o modelo de negócio durante o período de incubação.

- Empresa em fase inicial de incubação: empresa com menos de 2 meses de início das operações no programa de incubação.

O próximo procedimento metodológico foi a investigação das inovações geradas. Para tanto realizaram-se entrevistas com os empresários atendidos, buscando apurar:
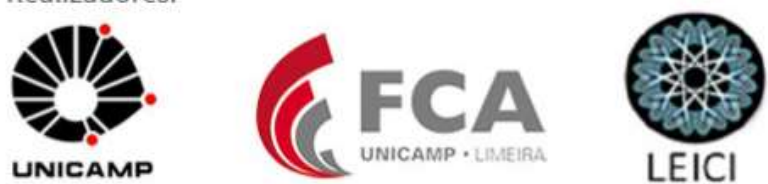
- A intensidade e a profundidade dos impactos das inovações. Utilizando a classificação de Schumpeter de inovações incrementais - introdução de mudanças relativamente marginais ou de menor escala na concepção de um produto ou de um processo existente - e inovações radicais - aquelas baseadas em desvios significativos em relação ao design existente e à concepção do produto (RADAS; BOŽIĆ, 2009; VELU, 2014);

- Os processos por meio dos quais as inovações foram geradas e difundidas. Para tanto se analisou o grau de interatividade das empresas inovadoras com os analistas da incubadora. A fim de avaliar estas interatividades procedeu-se à aplicação da tipologia de grau de intensidade desenvolvida por Fonseca (2010) e adaptada para este trabalho. Segundo esta tipologia as relações foram classificadas em 5 graus, onde em um dos extremos está a dependência total onde os estímulos e os apoios da incubadora foram absolutamente essenciais para que o empreendimento inovasse ou, em outras palavras, o empreendimento não inovaria caso não estivesse na incubadora; e no outro está a classificação nenhuma dependência - o empreendimento inovou com independência total do programa;

- As iniciativas dos programas para as inovações. Segundo Fonseca (2010), na gestão da inovação as incubadoras podem adotar cinco posturas: podem ser proativas; podem atuar na gestão; podem ser reativas; podem realizar o monitoramento; ou podem se manter distantes do processo inovador. Partindo-se desta classificação, buscou-se analisar a postura da Incubadora junto a cada empresa. Como proativos foram enquadrados os casos em que o programa tomou iniciativas de alertar as empresas para a necessidade de inovar, realizou atividades indutivas permanentes, identificou e buscou fontes de recursos, técnicos, materiais e financeiros; gestão - aproximou as empresas com outros agentes técnicos externos, oferecendo apoio à elaboração de projetos e responsabilizando-se pela gestão da infraestrutura de suporte à inovação; reatividade - ofereceu apoio sempre que demandado; monitoramento - apenas acompanhou os processos; ou distanciamento - não interferiu.

$\mathrm{O}$ terceiro procedimento metodológico correspondeu à um mix de pesquisa documental e entrevistas, a fim de investigar os tipos de serviço que cada empresário teve acesso, a influencia do ambiente institucional do desempenho do empreendimento, com a respectiva caracterização da existência, ou não de vazios institucionais; a qualidade do serviço fornecido; a participação dos empreendedores; e as características culturais do ambiente.

Acentua-se que na realização da pesquisa, foram entrevistados 38 empreendedores e 4 membros da equipe de gerenciamento da incubadora. É válido ressaltar ainda, que um percentual dos empreendedores entrevistados, já haviam sido graduadas pelo programa de incubação e que a pesquisa coletou informações referentes a penas ao período em que estes estavam sendo assistidas pela incubadora. Buscou-se ainda, informações adicionais em relatórios de atividades, documentos consolidados, atas de reuniões e documentos normativos da incubadora investigada.

\subsection{Informações sobre o objeto de estudo}

A incubadora investigada foi criada em 1997 por meio de uma parceria estabelecida entre a Prefeitura Municipal, a Federação das Indústrias do Estado de São Paulo - FIESP e o Serviço Brasileiro de Apoio às Micro e Pequenas Empresas - SEBRAE. Ao todo a sua gestão

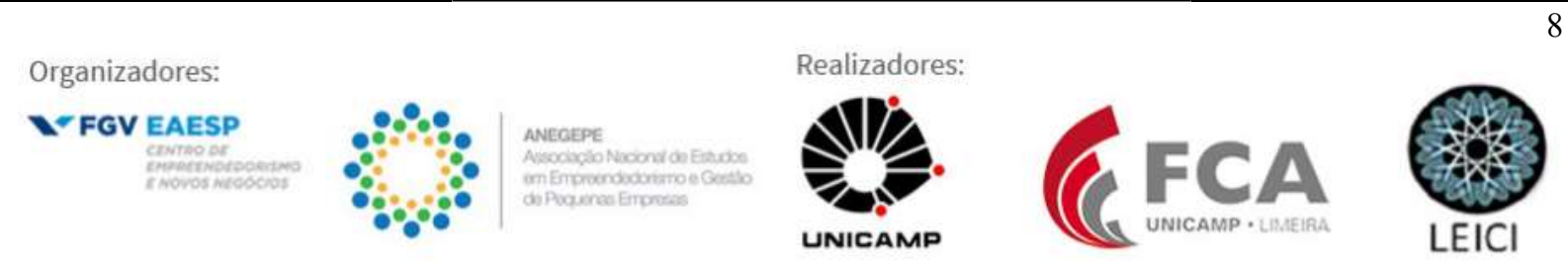


passou por quatro momentos; de 1997 a 2007 pela já citada FIESP; de 2008 a 2010 por um Instituto; entre 2011 e 2012 um outro instituto; e a partir de 2012 a responsabilidade pela gestão ficou a cargo de uma universidade estadual do estado de São Paulo. Institucionalmente a Incubadora de Empresas esta subordinada à pasta da Secretaria de Desenvolvimento Econômico da Prefeitura.

Atualmente os principais objetivos do programa são a criação de novos negócios, a geração de emprego e renda, a promoção da inovação e a articulação com as demais políticas públicas já desenvolvidas pela Prefeitura Municipal e outros agentes locais, de modo transversal e muitas vezes intersetorial. $O$ programa tem capacidade para atender 20 empresas por ciclo de incubação, sendo 6 associadas e 14 residentes. Cada empresa é incubada por um período que varia de e à 4 anos, dependendo das características e maturidade do modelo de negócio. Dentro da classificação tipológica, esta é uma incubadora do tipo pública, com perfil misto, gerida por uma universidade e mantida pelo poder público municipal.

\section{Resultados}

Os resultados da pesquisa mostram duas dimensões, a primeira evidencia a análise estrutural da Incubadora, já a segunda refere-se à investigação das características das inovações geradas pelas empresas incubadas.

\subsection{Caracterização da gestão da incubadora: participação do empreendedor e desempenho do programa}

A gestão do programa investigado segue as diretrizes apresentadas pela gestão de projetos. Há uma cesta de serviços colocados à disposição dos empreendedores, porém, cada empresa tem acesso à uma cesta especifica, formatada de acordo com as peculiaridades de cada modelo de negócio. Entre os diferentes serviços entregues destaca-se a oferta de um diagnóstico gerencial, efetivado no inicio de cada ano. Este diagnóstico busca a identificação de lacunas na operacionalização do negócio e a elaboração de um plano de capacitações que pode incluir assessoria para elaboração de estratégias empresarias, formatação do modelo de negócios, elaboração de plano de negócios, consultoria financeira, mercadológica e jurídica; aproximação com agentes financeiros e inserção em redes. Tal como identificado em entrevistas, a equipa da incubadora elabora um plano de ação com cada empreendimento, e ao longo do ano monitora-se o desenvolvimento das metas estabelecidas. Ao longo da pesquisa foi evidenciado que o escopo de atuação da incubadora é ampliado continuamente, em respostas às demanda identificadas com cada empresário, foi citado como exemplo, o serviço de valuation, dado a demanda de um empreendimento, a equipe de consultores desenvolveu uma metodologia para ofertar o serviço requerido

Entre outubro de 2015 e novembro de 2017 foram atendidos 38 empreendimentos pela incubadora investigada, dos quais $68 \%$ como residente e $32 \%$ como associados. Constatou-se que $23,7 \%$ das empresas incubadas não acessaram a cesta de serviços ofertados pelo programa, usaram de forma esporádica as ações, a fim de atender demandas pontuais. Estas empresas, de forma geral, apresentavam características empreendedoras maduras, dispunham de uma sólida base de recursos e o suporte da incubadora não era demandado. Dentre os motivos que os levaram a procurar a incubadora se destacavam o subsidio financeiro, decorrente da taxa de incubação, que propiciava a locação de um espaço a custo reduzido. A

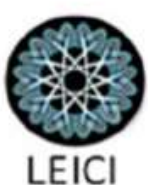


maturidade destes empreendimentos foi evidenciada nas entrevistas, quando os pesquisadores questionaram os recursos que faltavam para o desenvolvimento do empreendimento durante o período de incubação: a grande maioria dos entrevistados pertencentes à este grupo, não reconheciam recursos adicionais necessários. Este resultado corrobora os achados de Patton (2014) e Weele, Rijnsoever e Nauta, (2017), sendo um indicativo de que as incubadoras brasileiras precisarão desenvolver uma estratégia forte de intervenção, auxiliando os empreendedores a reconhecer suas lacunas de recursos e estimulando-os a desenvolver os recursos que faltam.

Já o segundo grupo de empresas, formado por empreendimentos que estabeleceram um plano de ação robusto, com intervenções em diversas áreas, destacaram que o principal fator motivador da incubação foi a busca de um suporte para o desenvolvimento do empreendimento bem como a inserção assistida no movimento empreendedor. Os entrevistados pertencentes à este grupo reconheceram que diversos recursos ainda precisavam ser desenvolvidos, com destaque para o alcance da formalização da personalidade jurídica, o estabelecimento de planejamento estratégico, o desenvolvimento de forças de venda, a estruturação do departamento financeiro, o estabelecimento de um departamento de pesquisa, o desenvolvimento e implantação de sistema de qualidade e o acesso à financiamento e subvenções financeiras. Segundo a equipe de gerenciamento, todas essas demandas são sanadas pela incubadora, tanto internamente quanto pela rede de parceiros, com exceção à formalização visto que são emitidos esforços para auxiliar o empreendedor em termos processuais, contudo, o pleno alcance da formalização é dependente da estrutura estatal que fiscaliza e emite as licenças de funcionamento. Da mesma forma, o acesso à subvenções e ao financiamento, contatou-se que a incubadora disponibiliza informações sobre as linhas de incentivo disponíveis e auxilia na solicitação dos mesmos, porém, a disponibilização dos recursos envolvem dimensões externas ao ambiente incubador.

A investigação indicou que as empresas incubadas encontram dificuldades para regularização jurídica. Sendo este um processo lento e extremamente burocrático. Como diagnosticado pela pesquisa, das 12 empresas residentes em novembro de 2017, a penas 2 estavam totalmente regularizados, com o alvará de funcionamento emitido. As 10 restantes estavam esperando fiscalização de diversos departamentos, como exemplo cita-se os fiscais sanitários, do meio ambiente e do ministério da Agricultura. Este processo acabou ampliando em muito o ônus burocrático da formalização (entendido como custo e tempo necessário), tornando-se barreiras ao completo desenvolvimento empresarial (HALABÍE; LUSSIER, 2014). Tal ônus levou um empreendimento à mortalidade: por 18 meses o empreendimento ficou aguardando o aval da CETESB, o que inviabilizou a continuidade da empresa dado a impossibilidade de comercialização. Outro exemplo deste ônus foi observado na realidade enfrentada por uma empresa da área médica que esperou, em média, 22 meses para alcançarem a licença de comercialização de produtos inovadores. A explicação para este quadro encontra respaldo na teoria institucional, as economias em desenvolvimento são caracterizadas por vazios institucionais; geralmente são economias que estão associadas com um campo do direito pouco definido, principalmente nas questões relacionadas à propriedade, aos contratos e à corrupção desenfreada. Frequentemente apresentam serviços públicos pouco efetivos e aparelhos de execução ineficientes (WEBB; IRELAND; KETCHEN, 2014).

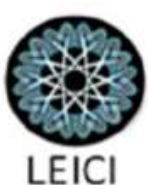


Em relação as solicitações de financiamento, os empresários investigados relataram que as opções disponíveis não atendem as demandas dos empreendimentos, geralmente precisam de capital de giro, cujas taxas de juros sobre são demasiadamente altas e a obtenção acaba demandando uma série de requisitos que dificultam a aquisição. Este cenário acaba sendo um risco, pois quando os empresários são incapazes de obter financiamento, muitas vezes são levados a recorrer a empréstimos pessoais, o que parece não estar sempre no melhor interesse da empresa (RAMSEY et al., 2013; HAALABI; LUSSIER, 2014). Por outro lado, os editais de subvenções, todos ligadas à projetos inovadores, quando disponíveis são apresentados aos empreendedores e os projetos são submetidos, porém são editais restritos às empresas tecnológicas, colocando à margem um percentual significativo das empresas atendidas. De forma ilustrativa, delimita-se que no momento em que esta pesquisa foi realizada, somente $15 \%$ das empresas incubadas no ciclo vigente estavam executando projetos de subsídios.

\subsection{Empresas incubadas e o processo inovador}

Como apresentado na seção anterior, entre outubro de 2015 e novembro de 2017 foram atendidos 38 empreendimentos pela incubadora investigada, no quadro 1 sintetiza-se o mapeamento destas empresas, a partir do cruzamento de duas variáveis: inovações e participação nas atividades de treinamento.

\begin{tabular}{|c|c|c|c|c|}
\hline $\begin{array}{l}\text { Empresas não } \\
\text { atendidas e que } \\
\text { não inovaram }\end{array}$ & $\begin{array}{l}\text { Empresas não } \\
\text { atendidas e } \\
\text { que inovaram }\end{array}$ & $\begin{array}{l}\text { resas } \\
\text { didas e que } \\
\text { novaram }\end{array}$ & $\begin{array}{l}\text { Empresas } \\
\text { atendidas e } \\
\text { que inovaram }\end{array}$ & $\begin{array}{l}\text { Empresas em } \\
\text { fase inicial de } \\
\text { incubação }\end{array}$ \\
\hline $\begin{array}{l}7 \quad \text { empresas } \\
(18,4 \%)\end{array}$ & $\begin{array}{l}2 \text { empresa } \\
(5,3 \%)\end{array}$ & $\begin{array}{l}7 \quad \text { empresas } \\
(18,4 \%)\end{array}$ & $\begin{array}{l}22 \text { empresas } \\
(57,9 \%)\end{array}$ & \\
\hline
\end{tabular}

Quadro 1 - Classificação tipológica das empresas incubadas.

Fonte: Elaboração própria com base nos resultados da pesquisa (2018)

Como pode ser observado, $63 \%$ das empresas incubadas no período analisado inovaram, contudo, em dois casos, as inovações independeram da incubadora. No próximo quadro, evidencia-se uma síntese de como o processo inovativo ocorreu.

\begin{tabular}{|c|c|c|c|c|c|}
\hline Empresa & $\begin{array}{c}\text { Empresa } \\
\text { com vocação }\end{array}$ & Tipo de inovação & $\begin{array}{c}\text { Intensidade da } \\
\text { inovação }\end{array}$ & $\begin{array}{c}\text { Grau de } \\
\text { dependência }\end{array}$ & $\begin{array}{c}\text { Iniciativas dos } \\
\text { programas }\end{array}$ \\
\hline $\begin{array}{c}\text { Empresa 5, } \\
15 \text { e 20 }\end{array}$ & Tecnológica & Produto e processo & $\begin{array}{c}\text { Alta } \\
\text { complexidade }\end{array}$ & $\begin{array}{c}\text { Alta } \\
\text { dependencia }\end{array}$ & $\begin{array}{c}\text { Pró atividade e } \\
\text { Gestão }\end{array}$ \\
\hline $\begin{array}{c}\text { Empresa } \\
17 \text { e 23 }\end{array}$ & Tecnológica & Produto e processo & $\begin{array}{c}\text { Alta } \\
\text { complexidade }\end{array}$ & $\begin{array}{c}\text { Baixa de } \\
\text { pendência }\end{array}$ & Gestão \\
\hline $\begin{array}{c}\text { Empresa } 9 \\
\text { e 24 }\end{array}$ & Tecnológica & Produto & $\begin{array}{c}\text { Alta } \\
\text { complexidade }\end{array}$ & $\begin{array}{c}\text { Baixa } \\
\text { dependencia }\end{array}$ & Reativos \\
\hline $\begin{array}{c}\text { Empresa } \\
12,14 \text { e 18 }\end{array}$ & Tecnológica & Produto & $\begin{array}{c}\text { Alta } \\
\text { complexidade } \\
\text { dependencia }\end{array}$ & Monitoramento \\
\hline $\begin{array}{c}\text { Empresa } \\
19\end{array}$ & Tecnológica & Produto & $\begin{array}{c}\text { Alta } \\
\text { complexidade }\end{array}$ & $\begin{array}{c}\text { Baixa } \\
\text { dependencia }\end{array}$ & Indiferentes \\
\hline $\begin{array}{c}\text { Empresa } \\
1,3,4,7, \\
11,13 \text { e 16 }\end{array}$ & Tradicional & $\begin{array}{c}\text { Organizacional e } \\
\text { Produtos }\end{array}$ & $\begin{array}{c}\text { Baixa } \\
\text { complexidade }\end{array}$ & $\begin{array}{c}\text { Alta } \\
\text { dependencia }\end{array}$ & $\begin{array}{c}\text { Gestão e } \\
\text { Proatividade }\end{array}$ \\
\hline
\end{tabular}
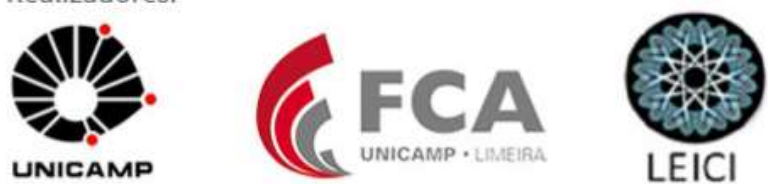


\begin{tabular}{|c|c|c|c|c|c|}
$\begin{array}{c}\text { Empresa 2, } \\
8 \text { e 10 }\end{array}$ & Tradicional & Processo e Produto & $\begin{array}{c}\text { Baixa } \\
\text { complexidade }\end{array}$ & $\begin{array}{c}\text { Média } \\
\text { dependencia }\end{array}$ & Gestão \\
\hline $\begin{array}{c}\text { Empresa } 6 \\
\text { e 21 }\end{array}$ & Tradicional & $\begin{array}{c}\text { Organizacional e } \\
\text { Processo }\end{array}$ & $\begin{array}{c}\text { Baixa } \\
\text { complexidade }\end{array}$ & $\begin{array}{c}\text { Baixa } \\
\text { dependencia }\end{array}$ & Reativos \\
\hline $\begin{array}{c}\text { Empresa } \\
22\end{array}$ & Tradicional & $\begin{array}{c}\text { Organizacional, } \\
\text { Produto e Processo }\end{array}$ & $\begin{array}{c}\text { Baixa } \\
\text { complexidade }\end{array}$ & $\begin{array}{c}\text { Baixa } \\
\text { dependencia }\end{array}$ & Indiferente \\
\hline
\end{tabular}

Quadro 2 - Classificação das empresas pelo processo inovador.

Fonte: Elaboração própria com base nos resultados da pesquisa (2018)

A pesquisa revelou que a atuação da incubadora vai muito ao encontro da vocação do empreendimento: empresas assistidas e que tinham vocações tecnológicas, muitas das quais constituídas através do modelo spin off, geraram inovações em produtos, de alta complexidade, com baixa dependência da incubadora e com aporte de subsídios financeiros de órgãos de fomento, tais como FAPESP e FINEP. Nas empresas enquadradas nesta categoria, a incubadora responsabilizou-se pela assessoria na elaborações de projetos e na elaboração do plano de comercialização. Por outro lado, empresas com vocação tradicional, atuantes em segmentos da economia já consolidados, geraram inovações de complexidade baixa, com total dependência da incubadora, de modo que a mesma se mostrou pró-ativa, alertando as empresas sobre as necessidades de inovações e responsabilizando-se por todo o aporte de recursos necessários.

De modo geral, $45 \%$ das empresas que inovaram geraram produtos/serviços de alta complexidade: cinco dessas empresas desenvolveram produtos inéditos na área da saúde, uma na produção de alimentos veganos, uma na área de processamento de dados da agricultura, duas desenvolveu um novo processo de produção de bebida destilada, uma atua na produção de energia renovável e a última na produção de equipamentos com tecnologia óptica embargada. As demais inovações geradas foram de baixa complexidade: em sua maioria, realizaram-se mudanças no formato do modelo de negócio (em alguns casos os empreendedores passaram a executar novas atividades econômicas e em outros focaram o seu modelo). Notou-se também que algumas empresas apresentaram mudanças nos processos de fabricação (ora por aquisição de equipamentos/automação, ora por adaptação de processo e por substituição de matéria-prima). Diversos autores chegaram a constatações equivalentes em suas pesquisas, a exemplo citam-se os estudos de Barge-Gil (2010); Heidenreich (2009), Nunes, Serrasqueiro e Leitão (2012) abordando inovações não tecnológicas ou inovações de baixa complexidade (low-tech innovations).

$\mathrm{Na}$ avaliação a respeito dos processos pelos quais as inovações foram geradas e difundidas, constatou-se que o grau de interatividade das empresas inovadoras com os analistas da incubadora foi considerado de dependência total em nove casos. Em virtude disso sugere-se que os estímulos e os apoios da incubadora foram absolutamente essenciais para que os empreendimentos inovassem. Esta avaliação foi justificada pelo fato de que, nesses casos, os empreendedores foram estimulados pela incubadora para a necessidade de inovarem e tiveram seus processos e produtos analisados cuidadosamente pela equipe do programa, que indicou o potencial de cada empresa e as possíveis fontes viabilizadoras de recursos adicionais para a inovação. Na sequência a equipe da incubadora passou a elaborar projetos, posteriormente submetidos a programas de apoio à inovação, como o PIPE (Programa Inovativo da Pequena Empresa) da FAPESP (Fundação de Amparo à Pesquisa do Estado de
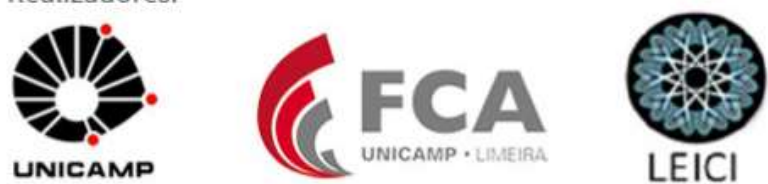
São Paulo) e o edital SEBRATEC do SEBRAE (Serviço Brasileiro de Apoio às Micro e Pequenas Empresas).

Em cinco casos o a incubadora estimularam e ofereceram importantes apoios para as inovações, embora tenha se constatado que as empresas teriam condições de inovar de forma independente. Em ambos os casos as inovações geradas foram de baixa complexidade, sem que fossem elaborados projetos. Nos demais casos a dependência das empresas foi considerada média ou baixa uma vez que os apoios foram oferecidos apenas quando demandados.

A literatura aponta que algumas competências são necessárias para a inovação, entre as quais se destacam: a presença de um corpo de profissionais especializados e qualificados; a forte liderança dos responsáveis pela organização; a existência de estratégias e planejamento para o futuro; as atividades de pesquisa e desenvolvimento (D'ESTE et al., 2012; RADAS; BOŽIĆ, 2009). São competências necessárias para o diálogo e a colaboração com outras empresas, para a manutenção de relações de cooperação para a pesquisa, para a transferência de tecnologia com as universidades e os centros de pesquisa e para a captação de recursos financeiros ou demais tipos de apoios governamentais (D'ESTE et al., 2012; RADAS; BOŽIĆ, 2009). Os resultados desta pesquisa evidenciam que a parceria da Incubadora com outras instituições (universidades estaduais e federais, centros de inovações e programas de incentivo tal como o Serviço Brasileiro de Resposta Técnica e o Serviço Brasileiro de Apoio às Micro e Pequenas Empresas) teve, como uma de suas consequências, o estímulo ao desenvolvimento dessas competências nas empresas assistidas - com maior intensidade nas empresas com maior grau de dependência.

Este resultado confirma as conclusões de D'Este et al. (2012) e Love, Roper e Vahter (2014) de que a inovação depende crucialmente da capacidade das empresas de absorverem conhecimentos externos, combinando-os com seus próprios conhecimentos, tácitos ou explícitos. Além do mais, é um resultado que corrobora também com os postulados da literatura de inovação estratégica que reconhece, cada vez mais, que a combinação de fontes de conhecimento interno e externo é um elemento-chave de uma estratégia de inovação bemsucedida (LOVE; ROPER; VAHTER, 2014). Assim, confirma-se, neste trabalho, que um elemento importante no processo inovador (seja ele de alta ou baixa complexidade) é a identificação e o aproveitamento de conhecimentos complementares entre diferentes atividades situadas dentro e fora dos limites da empresa. Tomando-se como variável analítica o grau de pro atividade da incubadora, constatou-se que das 24 empresas que apresentaram inovações, em quinze casos (62\%) os programas tomaram a iniciativa de alertar as empresas para a necessidade de inovar, realizando atividades indutivas permanentes, identificando e buscando fontes de recursos, técnicos, materiais e financeiros, atuando hora co proa atividade e hora na gestão da inovação. Por outro lado, em três empresas (12\%) constatou-se que apenas o monitoramento das ações inovativas foi realizado; e em quatro casos (16\%) os programas foram reativos.

\section{Considerações finais}

Duas principais conclusões emergem a partir da leitura dos resultados da pesquisa. A primeira, extraída do quadro 2 e consistente com grande parte dos indicativos da literatura, confirma a baixa propensão autônoma das micro e pequenas empresas não tecnologias para
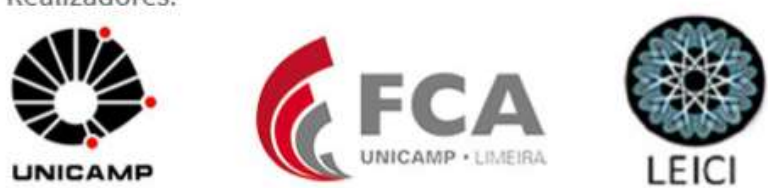
inovarem, evidenciada pela pequena proporção das empresas pesquisadas classificadas no extrato considerado de "baixa dependência" para com os aportes e contribuições das incubadoras. A segunda também converge com grande parte dos apontamentos da literatura, relativos à importância dos instrumentos e dos agentes de políticas públicas como indutores de condições passíveis de facilitarem a inovação no segmento das micro e pequenas empresas. Essa conclusão resulta da constatação da pesquisa quanto à efetividade, em termos dos resultados alcançados, das iniciativas e medidas tomadas pelo programa pesquisado. Em síntese, os resultados da pesquisa permitem apontar, em caráter conclusivo, que a atuação efetiva de mecanismos de políticas públicas pode contribuir fortemente para a quebra de barreiras e resistências para a geração ou a incorporação de inovações pelas micro e pequenas empresas - tanto tradicionais quanto tecnológicas.

Dentro da investigação foi analisado: a influência do ambiente institucional, com a respectiva caracterização da existência, ou não de vazios institucionais; a qualidade do serviço fornecido; a participação dos empreendedores; e as características culturais do ambiente. A fim de suportar esta análise, a próxima seção referencia brevemente o contexto da inovação em programas de incubação. De forma geral, percebe-se que o principal desafio de uma incubadora mista é atender os diferentes desafios impostos pelos diferentes perfis de empresas atendidas. Nas empresas com vocações tecnológicas o desafio esta ligado à retirada das mesmas das zonas de conforto em que se encontram, evidenciando os recursos que estão em falta e propiciando a oferta de serviços condizentes com as demandas reais destes negócios. Já para empresas com vocações não tecnológicas, o desafio principal é a introdução da cultura inovadora na rotina destas empresas, a pesar das mesmas terem maior propensão à participação nos programas de treinamento.

Observou-se ainda que os vazios institucionais, principalmente aqueles decorrentes da ineficiência do aparelho estatal em emitir licenças de funcionamento/fabricação, têm comprometido o desempenho das empresas incubadas, e, por conseqüência, o potencial para geração e incorporação da inovação na cultura empreendedora e na inserção da incubadora no ecossistema inovador.

Essas conclusões, embora convergentes com parcela não desprezível da literatura especializada, devem ser tratadas em caráter estrito, dadas as limitações, metodológicas e de abrangência da pesquisa. Isso implica o reconhecimento de que resultados e conclusões constantes deste texto não devem ser extrapolados a outros contextos.

\section{Referências}

ALSOS, G. A; HYTTI, U.; LJUNGGREN, E. Stakeholder theory approach to technology incubators. International Journal of Entrepreneurial Behaviour \& Research, v.17, n.6, p.607-625, 2011.

ADEGBITE, O. Business incubators and small enterprise development: the Nigerian experience. Small Business Economics, v.17, n.3, p. 157-166

AHMAD, A. J. A mechanisms-driven theory of business incubation. International Journal of Entrepreneurial Behaviour \& Research, v.20, n.4, p.375-405, 2014.

BARBOZA; FONSECA; RAMALHEIRO, 2017. O papel das políticas públicas para potencializar a inovação em pequenas empresas de base tradicional. REGE - Revista de Gestão, São Paulo, v.24, n.1, p.58-71, 2017.
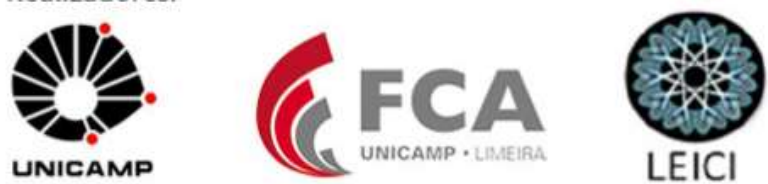
BARGE-GIL, A. Cooperation-based innovators and peripheral cooperators: An empirical analysis of their characteristics and behavior. Technovation, v.30, n.3, p.195-206, 2010.

BERGEK, A.; NORRMAN, C. Incubator best practice: A framework. Technovation, v.28, n.1-2, p.20-28, 2008.

BERMÚDEZ, L. A.; MORAIS, E. F. C. METODOLOGIA PARA avaliação ou autoavaliação de incubadoras e de empresas e de incubadas (high-technology ou low-technology).

Revista Espacios Digital, 1., 1988.

BHABRA-REMEDIOS, R. K.; CORNELIUS, B. Cracks in the Egg : improving performance measures in business incubator research. In:U. of Ballara (Ed.), Annual Conference of Small Enterprise Association of Australia and New Zealand, 2003, p. 1-19. Ballarat: University of Ballarat.

BRUNEEL, J. et al. The Evolution of Business Incubators: Comparing demand and supply of business incubation services across different incubator generations. Technovation, v.32, n.2, p.110-121, 2012.

CHAN, K. F.; LAU, T. Assessing technology incubator programs in the science park: the good, the bad and the ugly. Technovation, v. 25, p. 1215-1228, 2005.

CHESBROUGH, H. W. Open innovation: the new imperative for creating and profiting from technology. 1. ed. Boston: Harvard Business School Press, 2003.

D'ESTE, P. et al. What hampers innovation? Revealed barriers versus deterring barriers. Research Policy, v.41, n.2, p.482-488, 2012..

DOH, S.; KIM, B. Government support for SME innovations in the regional industries: The case of government financial support program in South Korea. Research Policy, v.43, n.9, p.1557-1569, 2014.

DUTT, N. et al.How open system intermediaries address institutional failures: the case of business incubators in emerging-market countries. Acad. Manag. J., 2015.

FONSECA, S. A. Modelo para a avaliação do desempenho e o apoio à gestão de incubadoras. 2010. 113 f. Tese (livre-docência) - Universidade Estadual Paulista, Faculdade de Ciências e Letras de Araraquara, 2010.

FURLANETTO, E. L. Desenvolvimento local integrado e sustentável: avaliação dos impactos do programa Sebrae de Incubadoras de empresas no estado da Paraíba. In: Simpósio de Gestão da Inovacão Tecnológica. Gramado: Anpad, 2006, p. 1-15.

HALABÍ, C. E.; LUSSIER, R. N. A model for predicting small firm performance: Increasing the probability of entrepreneurial success in Chile. Journal of Small Business and Enterprise Development.v.21, n.1, p.4-25, 2014

HEIDENREICH, M. Innovation patterns and location of European low- and mediumtechnology industries. Research Policy, v.38, n.3, p.483-494, 2009.

LALKAKA, R. Business incubators in developing countries: characteristics and performance Int. J. Entrep. Innov. Manag. v, 3, p. 31-55, 2003

Best practices in business incubation: Lessons (yet to be) learned, in: International

Conference on Business Centers, Actors of Economic and Social Development, Brussels, Belgium, 2001.

LOVE, J. H.; ROPER, S.; VAHTER, P. Dynamic complementarities in innovation strategies.

Research Policy, v.43, n.10, p.1774-1784, 2014. 
MC GUIRK, H.; LENIHAN, H.; HART, M. Measuring the impact of innovative human capital on small firms' propensity to innovate. Research Policy, v.44, n.4, p.965-976, 2015. MC KELVEY, M.; ZARING, O.; LJUNGBERG, D. Creating innovative opportunities through research collaboration: An evolutionary framework and empirical illustration in engineering. Technovation, v.39, p.26-36, 2014.

MIAN, S.; LAMINE, W.; FAYOLLE, A. Technology business incubation: an overview of the state of knowledge. Technovation, v.50-51, p.1-12, 2016.

MRKAJIC, B. Business incubation models and institutionally void environments. Technovation, v.68, p.44-55, 2017.

NUNES, P. M. M.; SERRASQUEIRO, Z.; LEITÃO, J. Is there a linear relationship between R\&D intensity and growth? Empirical evidence of non-high-tech vs. high-tech SMEs. Research Policy, v.41, n.1, p.36-53, 2012. em: 2 abr. 2015.

PATTON, D. Realising potential: the impact of business incubation on the absorptive capacity of new technology-based firms. Int. Small Bus. J., v.32, p. 897-917, 2014.

PATTON, D.; MARLOW, S. University technology business incubators: helping new entrepreneurial firms to learn to grow. Environ. Plan. C: Gov. Policy, v.29, p. 911-92, 2011. PAUWELS, C.; et al. Understanding a new generation incubation model: the accelerator.

Technovation, v.50-51, p. 13-24, 2016.

RADAS, S.; BOŽIĆ, L. The antecedents of SME innovativeness in an emerging transition economy. Technovation, v.29, n.6-7, p.438-450, 2009.

RAMALHEIRO, G. C. F.; FONSECA, S. A.; TERENCE, A. C. Um estudo sobre o desempenho de incubadoras em municípios do interior paulista. In: Encontro Nacional de Engenharia de Produção - ENEGEP, 30. Bauru. Anais... São Carlos, ABEPRO, 2010. p.1-14.

RATINHO, T.; HENRIQUES, E. The role of science parks and business incubators in converging countries: Evidence from Portugal. Technovation, v.30, n.4, p.278-290, 2010.

RICE, M. P. Co-production of business assistance in business incubators: an exploratory study. Journal of Business Venturing, v.17, n.2, p. 163-187, 2002.

RUBIN, T. H.; AAS, T. H.; STEAD, A. Knowledge flow in technological business incubators: evidence from Australia and Israel. Technovation, v.41-42, p. 11-25, 2015.

SCHUMPETER, J. A. Capitalismos, socialismo e democracia. Tradução: Ruy Jungmann. Rio de Janeiro: Editora Fundo de Cultura S.A., 1961. 488 p.

SPITHOVEN, A.; CLARYSSE, B.; KNOCKAERT, M. Building absorptive capacity to organise inbound open innovation in traditional industries. Technovation, v.31, n.1, p.10-21, 2011.

TÖDTLING, F.; LEHNER, P.; KAUFMANN, A. Do different types of innovation rely on specific kinds of knowledge interactions? Technovation, v.29, n.1, p.59-71, 2009.

VANDERSTRAETEN, V. MATTHYSSENS, P. Service-based differentiation strategies for business incubators: exploring external and internal alignment. Technovation, v.32, p. 656670, 2012.

VELU, C. Business model innovation and third-party alliance on the survival of new firms. Technovation, v.35, p.1-11, 2014.

WEBB, J. W.; IRELAND, R. D.; KETCHEN, D. J. Toward a greater understanding of entrepreneurship and strategy in the informal economy. Strategic Entrepreneurship Journal, v.8, n.1, p.1-15, 2014.

\section{Organizadores:}

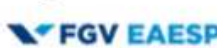

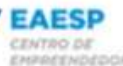

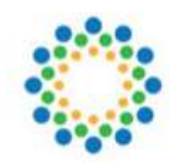

ANEabPe
Realizadores:
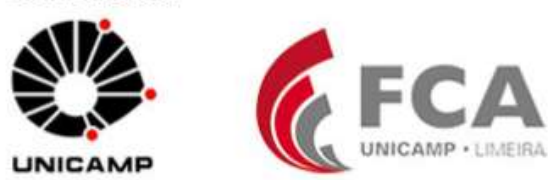